\title{
O entretenimento como arte séria: a revista MAD e a crítica ao consumismo
}

Entertainment as serious

art: MAD magazine and criticism of consumerism 


\section{Resumo}

O presente artigo estabelece relações entre a revista MAD, revista de humor norte-americana, e a hibridização entre a arte leve e a arte séria, segundo o pensamento de Andreas Huyssen. As duas esferas da arte serão problematizadas a partir da atualidade do conceito de indústria cultural e seu conjunto de ideais. $\mathrm{Na}$ sequência, abordaremos as características gerais da revista em busca de uma síntese com as ideias apresentadas. Por fim, tratar-se-á do tema do consumismo, que atravessa por diversas vezes a publicação, como uma forma de engajamento crítico, que é um atributo da arte séria, em reação aos mecanismos de dominação de uma sociedade baseada na cultura do consumo.

Palavras-chave: Indústria Cultural; Arte Séria; Arte Leve; Revista MAD; Consumismo

\section{Abstract}

This article establishes the connection between MAD magazine, a North America humor magazine, and the hybridization between ight art and serious art, according to Andreas Huysen's thoughts. The two art spheres will face problems with the current culture industry concept and its set of ideas. In the sequence, we will approach the general characteristics of the magazine as we look for a synthesis with the ideas we present. In summary, the article will discuss the theme of consumerism, which appears several times in the publication, as a form of critical engagement, which is an attribute of serious art, as a reaction to the domination mechanisms of a society based on the consumerism culture.

Keywords: Cultural industry; Serious Art; Light Art; MAD magazine; Consumerism 


\section{O entretenimento e a indústria cultural}

A relação entre o entretenimento e a diversão costuma ser imediata. Grosso modo, o ato de entreter-se pressupõe uma certa anestesia que, a rigor, se distancia da austeridade exigida nos diversos afazeres cotidianos. A diversão está próxima do ludus, isto é, da brincadeira como um divertimento. No entanto, conjugada ao entretenimento abarca uma variedade tão grande de atividades, cuja única semelhança, na maioria das vezes, é seu efeito relaxante. Nesse sentido, sua finalidade é como uma pequena pausa - um stop; ainda que paliativo, que permite desviar o olhar das preocupações e suavizar o peso dos processos que fragilizam e embrutecem a vida.

O termo ludus que é a raiz etimológica de palavras como lúdico e ludicidade, cujo campo de significação relaciona-se com os jogos em geral, sugere de modo ordinário os limites daquilo que consideramos sério ou leve. Para Johan Huizinga, a expressão latina além de suscitar o que atribuímos como não-sério, expressa uma realidade contrária à vida comum. Contudo, explica o autor, por mais que a seriedade busque excluir o ludus, ele pode plenamente harmonizar-se com a seriedade ${ }^{1}$. Portanto, ainda que pareçam contrários, a ludicidade e a seriedade não são fenômenos antagônicos.

Apesar das diferenças conceituais entre o divertimento e o lúdico - o primeiro mais livre e o segundo regido por regras - o divertimento é uma das maneiras mais fáceis de expressar o conceito de ludus. Portanto, por mais que o lúdico não seja o objeto principal deste estudo, a proposição de que o divertimento não necessariamente exclui a seriedade, oferece ao pensamento o suporte inicial para refletirmos o entretenimento como uma forma legítima de fazer artístico. Porquanto, se Huizinga (2004) identifica o elemento lúdico na poesia e na filosofia, equilibrando-se ambas entre leveza e seriedade, por que tal arranjo não pode ser encontrado naquilo que classificamos como entretenimento?

O entretenimento - filmes, rock and roll, literatura pulp, histórias em quadrinhos, televisão, jogos de computador, entre outros - classificam-se como um modo de arte leve, ancorados no conjunto de veículos de comunicação em massa ${ }^{2}$. Dada sua leveza e seu alcance, o entretenimento geralmente provoca certa antipatia nos círculos intelectuais. Se investigarmos o século XX, encontramos Adorno e Horkheimer como os principais autores que repudiaram a experiência estética do entretenimento.

A proposta dos autores alemães foi correlacionar os termos "indústria" e "cultura" com o intuito de substituir o conceito de cultura de massa. Por não se tratar de uma cultura que nasce do povo, destacam a verticalização, de cima para baixo,

1 HUIZINGA, Johan. Homo Ludens: o jogo como elemento da cultura, 2004, p. 51.

2 GABLER, Neal. Life: The Movie: How Entertainment Conquered Reality, 2000, p. 11-21. 
dos processos de criação e de dominação, nos quais as massas abandonam a própria criatividade em detrimento do consumo ${ }^{3}$. A substituição do termo cultura de massa por indústria cultural não reflete apenas o abandono destacado por Rodrigues, pois o conceito de indústria cultural pressupõe certa incapacidade das massa em produzir uma cultura não alienada, isto é, emancipatória. Do mesmo modo, a crítica presente na expressão dirige-se à forma como a mecanização e a padronização, que antes governavam apenas os processos de produção, estendem-se a todos os setores da vida social, inclusive a cultura e o entretenimento.

Para dupla de filósofos, o controle que a indústria cultural impõe em seus consumidores é uma ferramenta de alienação. Nessa perspectiva, o entretenimento produzido pela indústria não oferece os subsídios que conduzem a reflexão das contradições da sociedade, atuando, portanto, em defesa da ordem vigente. O indivíduo, diga-se entorpecido, não adquire as ferramentas para romper com sua prisão social, pois numa certa fuga do cotidiano a experiência não possibilita vicejar a resistência contra a ordem social estabelecida.

Aliás, entre os diversos predicativos que definem a expressão, está o casamento entre a cultura e o entretenimento ${ }^{4}$. O deslocamento da cultura para esfera do consumo transforma a arte numa atividade econômica que, como todo bom negócio, precisa ser vendida ao maior número de pessoas. Esse processo faz com que a arte se transforme num produto homogêneo e nivelador, que pode ser apreciado sem grandes esforços mentais. A padronização, a partir dessa prerrogativa, produz uma arte distraída que não exige do consumidor mais do que o exercício básico da passividade.

Apesar de Adorno e Horkheimer entenderem a cultura em sentido restrito, como o clássico e o erudito, o grande tema que perpassa o ensaio A Indústria Cultural é a relação entre a dominação e a cultura. O entretenimento é a diversão das massas. Divertir-se é estar distraído. A arte então banalizada, entendida como um objeto fugaz, cuja autonomia se submeteu à lógica de consumo, já não carrega em si os germes da transformação social, reforçando, portanto, as idiossincrasias de uma sociedade dividida em classes. Tal conceituação os levou a compreender a arte em duas categorias: a arte leve, descomprometida das grandes questões que atravessam a vida, logo, destinada ao divertimento, e a arte séria, contemplativa, que tem a capacidade de conduzir o indivíduo a uma consciência livre e emancipatória 5 .

3 RODRIGUES, Luciane Candido. A construção do conceito de Popular em Theodor Adorno, 2012, p. 10.

4 ADORNO, Theodor; HORKHEIMER, Max. Dialética do Esclarecimento: fragmentos filosóficos, 1985, p. 128.

5 Ibidem, p. 127. 
Pode parecerque Adorno e Horkheimer expressam um temperamento casmurro, contrários ao divertimento, contudo, isso não é verdade. Explica Ernest Mandel que o conceito de indústria cultural é uma crítica ao capitalismo tardio, reconhecido como um processo de "industrialização generalizada universal", que produz e determina quais produtos culturais os trabalhadores consomem em seus momentos de lazer ${ }^{6}$. O divertimento do público não é o problema, o perigo está no sistema determinar uma forma própria de diversão. Entretanto, para o teórico, a literatura revolucionária, por exemplo, tomada no espectro da arte séria, ao ser absorvida pelo mercado, ainda está submetida ao valor de uso. A expressão valor de uso, que é um importante termo no pensamento de Marx, deve ser incluída na equação sujeito-indústria, pois trata da relação subjetiva do consumidor com o produto, a qual independe dos meios de produção. Logo, sendo o valor de uso a maneira como o consumidor irá se relacionar com o objeto de consumo, a absorção da arte séria pela indústria cultural teria um efeito favorável em potencial. Mandel fala em nome de um marxismo ortodoxo, cuja revolução, ao final das contas, é um dos pilares do seu trabalho intelectual, e para tal objetivo, desde que atendesse à conscientização das massas, não há objeções em reduzir a arte revolucionária ao entretenimento.

Embora não houvesse percebido, os planos de Mandel já estavam em curso há mais de uma década antes de formular suas ideias. Determinados segmentos do que Adorno chamava de arte leve, já nos anos sessenta, começavam a trabalhar com maior criticismo, atuando a favor da conscientização do público, pois apareciam mesclados a atributos pertencentes à arte séria, num crescente processo de hibridização. No entanto, antes da continuação desse tema, ainda é preciso compreender o contexto em que o ensaio A Indústria Cultural foi concebido.

Explica Andreas Huyssen que o conjunto de ideias que cerca o termo indústria cultural já não encontra suporte na atualidade ${ }^{7}$ Em um cenário de Segunda Guerra, argumenta o autor, a crítica visava preservar a arte da instrumentalização de governos totalitários - como o uso do rádio pelo nazismo, por exemplo - ao mesmo tempo em que tinha por objetivo resguardar a arte, a partir da criação de fronteiras, daquilo que era a mera cultura comercial. A hostilidade para com a arte leve reflete um conjunto de tendências que busca reagir contra a cultura de massa e a mercantilização das artes, com o intuito de preservar o canônico e de purificá-lo da contaminação do popular. No entanto, nos dias de hoje, defende Huyssen, tal hostilidade já não encontra justificativa, pois a síntese entre a arte séria e a arte leve - como Adorno temia que acontecesse - tornou-se inevitável. Apesar do presente artigo expor e analisar

6 MANDEL, Ernest. O Capitalismo Tardio, 1985, p. 271.

7 HUYSSEN, Andreas. Memórias do Modernismo, 1997, p. 11. 
elementos que ultrapassam essa tensão - a partir da segunda seção do texto ao qual introduzimos a revista MAD - acreditamos que conceitos como alta arte, cultura de massa e hibridização são importantes para compreender as peculiaridades inerentes ao objeto em questão.

A análise de Huyssen baseia-se no fato de que as fronteiras entre aquilo que Adorno considerava sério e leve, entendidos como a alta arte e a cultura de massa, sofreram oscilações ${ }^{8}$. O desejo de resgatar as vanguardas europeias - das quais Adorno era um defensor - sob a égide de preservar o erudito, faz com que essa repetição seja automaticamente anacrônica, pois tanto as técnicas quanto os temas da alta cultura já foram pouco a pouco absorvidas pela cultura de massa. Portanto, para o teórico cultural, excetuando-se aquilo que é de fato kitsch, não existe mais aquela fronteira que separa os dois mundos, o "superior" e o "inferior", uma vez que o "inferior" já compartilha dos mesmos elementos do "superior" e vice-versa. Não se trata, percebase, da mercantilização da alta cultura como objeto de consumo, que está inserido no conceito de indústria cultural, mas da relação mútua em que os dois andares, o de cima e o de baixo, estabelecem enquanto formas de realização.

O diagnóstico de Huyssen não é, todavia, inovador. Adorno e Horkheimer já haviam previsto a fusão, contudo, com repúdio e desconfiança ${ }^{9}$. Para a dupla de Frankfurt, a absorção da arte séria pela arte leve, que é o objetivo da indústria cultural, faz parte dos processos de dominação e seu efeito, por conseguinte, é a propagação de uma má consciência social. No entanto, para Huyssen, persistir na redução do fenômeno a partir do maniqueísmo, além de enfraquecer a crítica - reforçando aspectos minimamente qualitativos - também traz consigo aquele velho medo da contaminação $^{10}$. Medo, inclusive, relembra o autor ${ }^{11}$, que não existia na década de 30 , quando então Walter Benjamin, também um representante da Escola de Frankfurt, defendia a crença numa cultura de massa emancipadora. Neste contexto, Andreas Huyssen recupera outra forma de pensar a cultura de massa, que já existia antes da Segunda Guerra, ao mesmo tempo em que defende o fato de o conceito "indústria

8 Ibidem, p. 37.

9 Adorno e Horkheimer, ao tratar das duas esferas da arte, considerando a arte leve uma sombra da arte autônoma, escrevem: "A pior maneira de reconciliar essa antítese é absorver a arte leve na arte séria ou vice-versa. Mas é isso que tenta a indústria cultural” (ADORNO, Theodor; HORKHEIMER, Max. Dialética do Esclarecimento: fragmentos filosóficos, 1985, p. 127).

10 Andreas Huyssen propõe corrigir certos desequilíbrios entre a crítica do modernismo e a do pósmodernismo. Segundo o autor, "Nem toda obra de arte que não se conforma às noções canonizadas de qualidade é automaticamente uma peça kitsch, e o trabalho de transformar o kitsch em arte sem dúvida resulta em obras de alta qualidade" (HUYSSEN, Andreas. Memórias do Modernismo, 1997, p. 10).

11 Huyssen, ao comparar o pensamento de Brecht ao de Benjamin, destaca que ambos - cada qual a 
cultural" ter sido criado sob um fenômeno social móvel. Sendo assim, apesar de toda sua importância para a teoria literária, a atualidade do termo demanda correções necessárias a partir das mudanças da sociedade.

A partir da década de sessenta, o entretenimento obliterou limites que estão além das fronteiras de uma arte distraída. Logo, a síntese entre a cultura de massa e a crítica social adquiriu uma fisionomia que não estava prevista no conceito cunhado por Adorno e Horkheimer. A investigação de Huyssen se debruça ante a obra de Andy Warhol e a Pop Art. No entanto, as qualidades críticas de uma arte leve podem ser encontradas em diversas mídias de comunicação em massa. Este trabalho optou por observar esse fenômeno a partir da revista de humor norte-americana Mad Magażine, daqui pra frente, portanto, nossa atenção volta-se para um novo objeto.

\section{A MAD Magazine}

A revista MAD, que em 2019 anunciou seu fim nos Estados Unidos, após sessenta e sete anos de publicação, e que circulou por cerca de vinte países ${ }^{12}$, foi uma das mais icônicas revistas de humor do mundo. Sua primeira edição, em outubro de 1952, já anunciava na capa o tom mordaz da revista, "humor na veia jugular"13, e o clima satírico que conjugaria o riso às loucuras da vida contemporânea: "histórias meticulosamente elaboradas para levá-lo à LOUCURA"14. O humor subversivo e questionador, tão característico da revista, foi um pioneiro nas formas de se fazer sátiras na modernidade, num contexto de crescente expansão da cultura de massa, que com raras exceções, como é o caso do rock and roll, era complacente e conformista ${ }^{15}$.

Ao longo das primeiras três décadas, o período de ouro da publicação, a revista MAD foi um produto para jovens céticos e desiludidos com a sociedade. Segundo Tony Hiss (1977), colunista do The New York. Times, num contexto de 1952, quando a revista surgiu nos Estados Unidos, a MAD ensinou aos seus leitores que tudo era questionável: "que havia mentiras na publicidade, que os demais veículos de humor mentiam, que a televisão e o cinema mentiam, que os adultos, em sua grande maioria,

seu modo - "tendiam a fetichizar a técnica, a ciência e a produção na arte, esperando que as tecnologias modernas pudessem ser usadas para a construção de uma cultura socialista de massa" (Ibidem, p. 35).

$12 \mathrm{O}$ corpus utilizado para esta pesquisa foram as publicações da revista $M A D$ em Português, como foram batizadas no Brasil, na década de setenta, pela Editora Vecchi.

13 No original: "humor in a jugular vein”. Tradução nossa.

14 No original: "Tales calculated to drive you MAD”. Tradução nossa.

15 THOMPSON, Ethan. Parody and Tasty in Postwar American Television Culture. Routledge, 2011, p. 46. 
quando tinham de enfrentar o desconhecido, por conseguinte, mentiam também"16. Para Tom Kock, humorista que colaborou com a revista por mais de trinta anos, o leitor da MAD, numa linguagem figurada, é aquela pessoa introvertida que acena pra sociedade e diz, desculpe-me, estou de saída ${ }^{17}$. Particularidades à parte, fossem céticos ou desiludidos, rebeldes ou introvertidos, o humor produzido pela MAD reunia um público jovem e insatisfeito, de uma forma ou de outra, com os rumos e os tropeços da civilização.

Apesar de ser uma revista destinada ao público jovem, que satiriza ícones do cinema, da música, da televisão e dos quadrinhos - as famosas sátiras contra a cultura de massa -, seu humor subversivo, por outro lado, soube como refletir o descontentamento e o desassossego dos diversos movimentos de juventude e rebeldia que marcaram a época. Além disso, a revista declarava que nada, para ela, era sagrado, "nada, nada, nada"18; de modo que não poupava satirizar, fosse o que fosse, desde celebridades, figuras políticas, personagens em quadrinhos, instituições religiosas, bons costumes ou qualquer princípio de moralidade.

De fato, ao folhear as páginas da revista, encontra-se muito do que seu editor no Brasil, Otacílio Costa d'Assunção (2017), chama de crítica dos costumes. Não apenas os bons costumes, diga-se de passagem, mas um conjunto de valores baseados nos movimentos de contracultura que tinham, em suas mais diversas correntes, um apelo contra o autoritarismo, o armamentismo, a cultura da guerra e as relações de poder.

Destaca-se que as décadas de sessenta e setenta foram o auge dos movimentos contraculturais, de acentuada participação jovem na política, que determinou o perfil da revista, a ponto de seus detratores, ainda que a publicação não tivesse alianças partidárias, enquadrarem-na como propaganda comunista ${ }^{19}$. Talvez seja fácil perceber o motivo, pois entre os principais temas da MAD, durante as duas décadas, estavam o anticonsumismo, o antitabagismo, o antiarmamentismo, as causas ecológicas, o psicodelismo, o direito das mulheres e, em geral, tudo aquilo que era facilmente identificado com os movimentos contraculturais. No entanto, pela falta de um alinhamento político-partidário mais evidente, a revista também ficou conhecida, entre os especialistas, como uma publicação de menor conteúdo ideológico. Tal opinião é

16 No original: "that there were lies in advertising, that other comic hooks lied, that television and movies lied, and that adults, in general, when faced with the unknown, lied”. Tradução nossa.

17 KOCK, Thomas Freeman. “Que é um introvertido?” Revista MAD em Português, 1974, p. 36-37. 18 REINT, Sy. "A Cartilha MAD da Poluição”. Revista MAD em Português, 1975, p. 23.

19 WELCH, Susan; GRUHL, John; COMER, John, RIGDON, Susan. Understanding American Government, 2008, p. 474. 
compartilhada, por exemplo, por Dorinho Bastos ${ }^{20}$, professor do curso de Publicidade da USP, e d'Assunção (2017), principal editor da revista no Brasil, que valorizam a natureza satírica da revista e sua forte crítica à cultura pop. A respeito disso, o roteirista e escritor Max Jacobs ${ }^{21}$ afirma:

\footnotetext{
Mad é um animal estranho. Porque ela contém muitos desenhos, muita gente a chama de [revista de] quadrinhos. Pelo fato de agradar a muitos jovens, as pessoas pensam que não é uma leitura adequada para adultos. Por atacar ambas as tendências políticas, é demonizada por todas elas. Uma vez que ataca instituições sagradas, é chamada de antiamericana. Porque se recusa a publicar pornografia, é chamada de careta. Já que bate em tudo, é acusada de carecer de um ponto de vista ${ }^{22}$.
}

Ou seja, por criticar as tendências de direita e de esquerda, preservando a independência entre ambas, a revista MAD é classificada como não ideológica, o que significa dizer não engajada. Todavia, a manutenção desse discurso corrobora com a tese que a arte leve, que visa o entretenimento, não oferece as vicissitudes que provocam o pensamento emancipatório, pois, em última análise, conforme demonstra o conceito de indústria cultural, a função do entretenimento é a preservação do status quo. Portanto, deveria-se refletir sobre o que significa a ideologia ou o engajamento e, para isso, as contribuições de Raymond Williams são apropriadas. Para o teórico, o ponto de partida na construção do conceito de ideologia, no pensamento de Marx, é o hegelianismo, que concebia a pré-existência de ideias independentes (ou anteriores) ao ato de consciência ${ }^{23}$. Por isso, quando escreveu sobre o engajamento dos escritores, destacou que o marxismo, mais do que qualquer outro sistema filosófico, demonstrou como estamos engajados muito antes de percebermos que estamos engajados ${ }^{24}$. Tal afirmação já é suficiente para inferir que, segundo Williams, o discurso não ideológico não existe. Mas Williams vai além, para o britânico, engajar-se significa tomar a consciência real dos alinhamentos que já possuímos ${ }^{25}$, significa tomar consciência

20 SALGADO, Daniel. “O “fim” da MAD, maior revista de humor do mundo". Época, 2019.

21 Max Jacobs apud SANTOS, Roberto Elísio dos. Uma revista muito louca: análise do humor da MAD Magazine, 2015, p. 154.

22 No original: "Mad is a strange animal. Because it contains so many pictures, many people call it a comic. Because it appeals to so many youngsters, many people think it is not fit reading for adults. Because it assails both political fringes, it is damned by both of them. Because it attacks sacred institutions, it is called un-American. Because it refuses to print pornograpy, it is called square. Because it hits everything, it is accused of lacking a point of view".

23 WILLIAMS, Raymond. Marxism and Literature, 1978, p. 54-56.

24 Idem, 2015, p. 127.

25 Ibidem, p. 129. 
das ideias prévias que edificam nosso ser e, neste sentido, a ideia de submissão a um partido político torna-se pueril.

Tratar do engajamento da revista MAD, portanto, não significa exatamente o alinhamento com um partido político. Destaca-se que entre os temas que circulavam pela revista, o anticonsumismo certamente era um dos mais próximos de uma agenda revolucionária. Aqui podem surgir controvérsias. Por exemplo, o período áureo da publicação que chegou a registrar a venda de dois milhões de exemplares, ainda que custasse quarenta centavos, representava muito dinheiro. No entanto, é preciso lembrar que a MAD se recusava a inserir propagandas em suas páginas. O motivo é simples, a propaganda é a alma do negócio e o objetivo final do marketing não é senão o consumo. Mas além disso havia outras duas razões.

Harvey Kurtzman, o criador da revista, já previamente recusava que seus quadrinhos, desde a época em que trabalhava com o gênero de terror, recebessem propagandas ${ }^{26}$; tal era sua forma de trabalhar. Para Hugh Hefner's, famoso criador da revista Playboy, que era admirador da obra de Kurtzman e, inclusive, o contratou para trabalhar com sua revista Trump, associar qualquer propaganda às sátiras de Kurtzman, seria no mínimo inconsistente. Kurtzman, dizia o editor, era alguém que buscava a pureza na obra de $\operatorname{arte}^{27}$. A segunda razão, no entanto, parte de outro importante nome na história da revista. Para William Gaines, editor-proprietário da EC Comics, responsável pela publicação, havia um motivo pelo qual a revista MAD recusasse anunciantes: seguir a tradição do PM Newspaper, jornal nova-iorquino que encerrou a circulação em 1948, o qual buscava na falta de anunciantes maior liberdade criativa e autonomia contra as pressões do sistema ${ }^{28}$. Assim como a MAD - enfim, também fora chamado de comunista.

Relacionar o fato que Harvey Kurtzman recusava a associação de propagandas com suas obras para construção de uma arte séria parece desnecessário. No entanto, é preciso explorar um pouco mais o assunto. Kurtzman, que cursou o Ensino Médio em uma instituição voltada à criação artística, a The High School of Music \& Art, dominava a técnica do que chamamos aqui de arte séria. $O$ cartunista encerrou sua participação na revista em 1956, contudo, todas as características que fariam com que a revista MAD fosse a MAD já haviam sido ditadas por ele. Logo, observa Roberto Elísio dos

26 SCHELLY, Bill. American Comic Book Chronicles: the 1950s, 2013, p. 85.

27 Idem, 2015, p. 344.

28 MEYERSON STRATEGY: MAD Magazine founder William M. Gaines Interviewed in 1978. Entrevistador: Charlie Meyerson. Entrevistado: William Gaines. Chicago: ComiCon, 15 jul. 1978. 
Santos que quase todos os autores envolvidos com a produção da revista, assim como Kurtzman, tiveram uma sólida formação no estudo das artes ${ }^{29}$.

Concluído o entendimento que a produção da revista era realizada por pessoas com conhecimento de causa e estudo formal no seio das artes, o tema do consumismo, entretanto, ainda revela novas facetas. Mas para alçá-las é preciso explorar um pouco mais a questão da ausência de propagandas. Aqui algumas recordações são pertinentes, para Adorno e Horkheimer, a diversão e o entretenimento representam uma apologia da sociedade ${ }^{30}$. No entanto, a dupla de Frankfurt faz o uso da palavra "apologia" no sentido de propaganda, pois para a indústria cultural, a propaganda e a indústria são duas faces da mesma moeda. A experiência estética, que se torna propaganda da sociedade de consumo, substitui uma experiência individual por uma genérica, objetivando igualmente a realização de um homem genérico, bis in idem, que oprime sua experiência social em detrimento de uma explicação divertida e propagandística do sistema. Apesar de Adorno e Horkheimer utilizarem a palavra "propaganda" num sentido muito particular, que não denota o anúncio pago em jornais, os motivos que fizeram a revista MAD dispensar as propagandas são muito semelhantes. Recusar o marketing de quaisquer produtos, no seio do capitalismo, é também anunciar sua independência ante a sociedade de consumo. Trata-se de um ato de resistência contra uma cultura de consumo que é um dos pilares do sistema capitalista.

Retornar a Ernest Mandel, neste momento, talvez seja um passo oportuno. Explica o autor que o capitalismo tardio expressa o ideal de uma sociedade arregimentada, isto é, dotada de regimentos sólidos que garantem o desenvolvimento econômico e social, de maneira equilibrada, entre todas as classes sociais. A proposição evidentemente é falsa. A sugestão de bem-estar faz parte do funcionamento do sistema. A propaganda, nesse sentido, oferece uma apologia de bem-estar social, no qual o sistema trabalha corretamente para garantir o acesso justo aos bens de consumo, o que não é verdade, pois trata-se em última instância de uma apologia da sociedade e do seu modus operandi.

29 SANTOS, Roberto Elísio dos. Uma revista muito louca: análise do humor da MAD Magazine, 2015, p. 123.

30 Para a dupla de filósofos, a finalidade entre os negócios e a diversão é a apologia de uma sociedade consumidora (ADORNO, Theodor; HORKHEIMER, Max. Dialética do Esclarecimento: fragmentos filosóficos, 1985, p. 134-135). 


\section{Como a MAD vê a sociedade do consumo?}

O título desta seção é uma paráfrase do estilo MAD de fazer humor. Por diversas vezes, os leitores tiveram contato com a interpretação que a revista tinha da sociedade através de sátiras do tipo: "[Como] MAD vê o símbolo do dólar" ou "[Como] MAD vê o casamento". A natureza crítica das sátiras buscava deflagrar aspectos confusos, senão negativos, da cultura americana. A atmosfera, de fato, é de insatisfação e muitas vezes de pesar, sobretudo, quando concerne a temas tão caros como a pobreza, a guerra, a corrupção e a injustiça. A terra do Tio Sam é uma propaganda mal resolvida, portanto, ao invés da apologia, a revista MAD escolheu sua maneira própria de independência: ainda que participasse da economia capitalista, não se confundia com ela.

Aqui convém uma recapitulação. Na década de setenta, a MAD custava vinte e cinco centavos de dólar. Era bimestral. Não havia propaganda. Seu criador recusava que sua arte dividisse página com objetos de consumo e, para seu editor, evitar a propaganda significava maior autonomia do sistema. Os antecedentes da revista eram propícios para que a equipe criativa satirizasse as falácias da sociedade do consumo. Nesse contexto, o tema do anticonsumismo tornou-se frequente, algo que acreditamos ser um engajamento presente desde a gênese da publicação, cuja consciência foi sendo desenvolvida pelos vários escritores e cartunistas que passaram pela revista. Sem o objetivo de esgotar o tema, vejamos a partir de agora o trabalho de alguns artistas que contribuíram com provocações que questionam a lógica de consumo da sociedade capitalista.

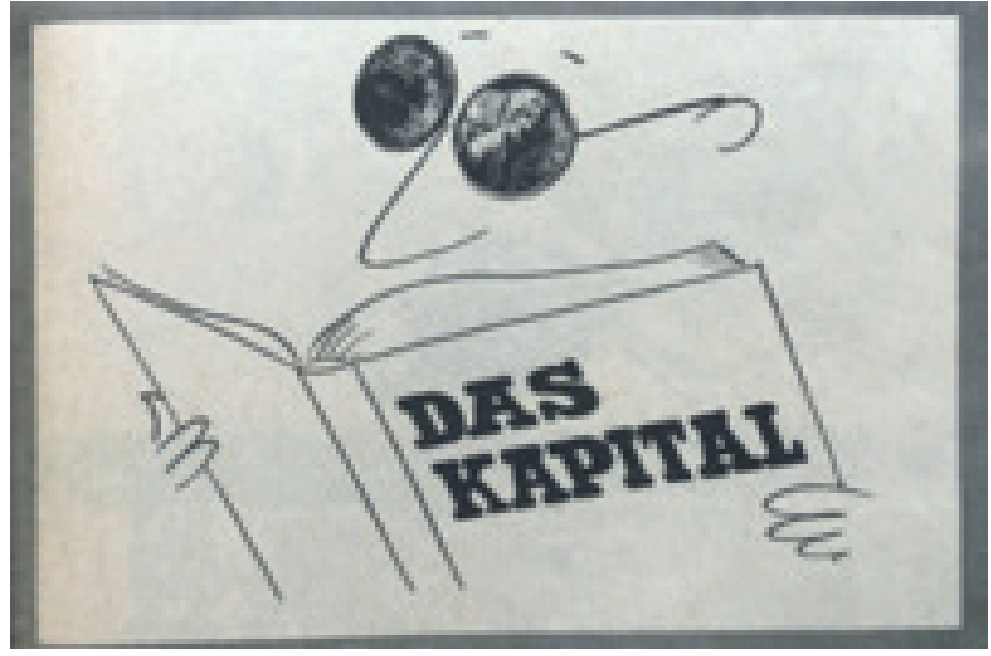

Fig. 1. FRANCHIONI, Arnoldo. $M A D$ vê o dinheiro. Fonte da figura: Revista $M A D \mathrm{em}$ Português, v. 6, 1974. 
A ideia de consumo, considerando sua dimensão etimológica, exibia até meados do século XIX significados negativos como exaurir, gastar ou destruir. A inversão dos pólos, do negativo para o positivo, aparece de maneira mais evidente sobretudo com a passagem do século. O novo entendimento está intimamente relacionado às necessidades da indústria capitalista ${ }^{31}$. O que significa dizer que a formação de uma sociedade guiada pelo consumo é um fenômeno historicamente construído. Logo, é possível inferir o destaque que Marx dá, em $O$ capital, à produção em detrimento do consumo, pois trata-se de um pensador par excellence do século XIX. Por mais que o filósofo tenha diferenciado entre consumo produtivo e consumo final, o primeiro relacionado à matéria-prima e o segundo ao lucro, falta-lhe, todavia, uma análise pormenorizada sobre a singularidade do consumo ${ }^{32}$.

O capital, livro que a personagem traz consigo na imagem anterior, é uma obra cujo conteúdo versa sobre uma "teoria geral” da acumulação capitalista. A sugestão do lucro, que Marx relaciona ao consumo final, está cravejada nos óculos da personagem, que se formam a partir do par de moedas de um centavo de dólar. A arte do cartunista argentino Arnoldo Franchioni (1928-2012), mais conhecido pelo codinome Francho, é acompanhada sempre de um verniz crítico. Seus principais temas são: a política, o sistema capitalista e o poder militar, que em síntese, o autor relaciona de maneira trinitária - "três-em-um" - no sistema capitalista. Na imagem acima, se Francho ironiza a leitura de O capital como um manual para quem busca multiplicar o seu dinheiro, é porque a obra oferece suporte filosófico sobre as bases do acúmulo financeiro. A construção do humor passa pelos centavos de dólar - que trazem o retrato de Abraham Lincoln - pois, apesar de ser a moeda de menor valor no sistema monetário americano, de grão em grão, e com uma boa teoria, a galinha enche o papo.

Vale lembrar que a imagem provoca o riso a partir de uma atribuição subjetiva: a de ler $O$ capital com uma mentalidade capitalista. $O$ valor de uso, que acompanha cada necessidade individual de consumo, propõe que o valor de um produto é mediado pela utilidade subjetiva que uma pessoa atribui ao item. Portanto, é a partir da interseção de $O$ capital, o dinheiro e a mentalidade capitalista, com sua incapacidade de enxergar senão o lucro, que Franchioni desenvolve seu humor.

Se a primeira imagem sugestiona a concentração de riqueza, a próxima traz consigo as consequências do acúmulo de capital. Fortuna pressupõe pobreza. Se os meios de produção asseguram o acúmulo financeiro, a pobreza decorre de múltiplos

31 FONTENELLE, Isleide Arruda. Cultura do Consumo: fundamentos e formas contemporâneas, 2017, p. $16-17$.

32 Ibidem, p. 178-179. 
fatores - políticos, econômicos, sociais e culturais. Podemos dizer que a pobreza é uma das maiores contradições do sistema capitalista, o qual fundamenta sua lógica sob a reprodução da desigualdade.
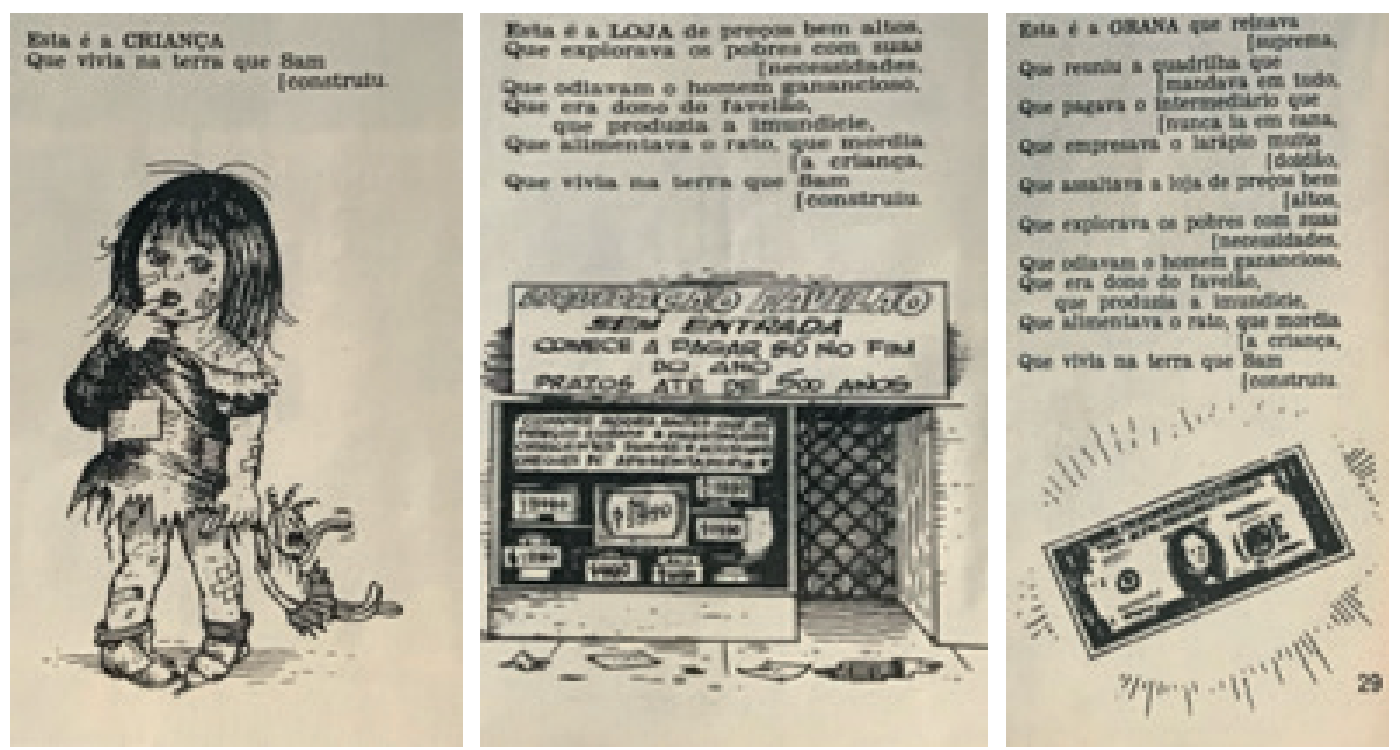

Fig 2. JAFFE, Al: JACOBS, Frank. Esta é a Terra que Sam Construiu. Fonte da figura: Revista MAD em Português, v. 20, 1976.

Ao tratar da relação entre o capitalismo e a desigualdade, um breve retorno a questões conceituais faz-se necessário. No pensamento de Adorno e Horkheimer, a experiência estética produzida pela indústria cultural busca propagandear a sociedade de consumo e, neste sentido, o sentimento de bem-estar é inevitável. Divertir-se, segundo a dupla, significa conformismo, pois contribui para que o sofrimento seja esquecido ${ }^{33}$. No entanto, no conjunto de imagens que compõem o trabalho de Al Jaffee (1921-*) e Frank Jacobs (1929-*), Esta é a Terra que Sam Construiu, não encontramos nenhuma apologia da sociedade, muito pelo contrário, a dupla de cartunistas tece quadro a quadro, uma narrativa que tem como grande vilão - numa lógica de causa e efeito - o poder do capital que organiza e controla o funcionamento da sociedade.

A obra em questão, da qual apresentamos apenas uma seleção de imagens, progride a partir de um elemento dêitico - esta é a Terra, esta é a criança, está é a grana - que além de recurso anafórico, aproxima o leitor da realidade apresentada. Sim, apesar do sonho americano ressaltar o contrário, a pobreza existe nos Estados Unidos. No primeiro quadro, é a boneca esfarrapada que expressa o desespero, enquanto a

33 ADORNO, Theodor; HORKHEIMER, Max. Dialética do Esclarecimento: fragmentos filosóficos, 1985 , p. 135. 
criança, com todas as suas chagas, preserva a serenidade. A imagem é provocativa. $\mathrm{O}$ apelo à sensibilidade, ao retratar uma criança, desconcerta o ideário de uma sociedade modelo. O Tio Sam, símbolo do poder financeiro e da sociedade privada, esconde naquilo que representa, as contradições de uma sociedade dividida em classes.

No segundo quadro, destaca-se a ironia contra as propagandas que prometem maior facilidade para realizar compras - sem entrada e quinhentos anos para pagar -, que não é senão, como revela o próprio texto, um sistema de exploração dos mais necessitados. A vitrine, que oferece televisões, simboliza o controle sobre a sociedade ${ }^{34}$. Nesse ponto, a filosofia de Adorno e Horkheimer e a visão de mundo da revista MAD confluem para um entendimento em comum. Enquanto os filósofos classificam a televisão como "retardada" 35, a programação, o controle e a falta de conteúdo são temas recorrentes na revista. No entanto, o âmago da crítica é a exploração da pobreza. Ao oferecer crédito e explorar os humildes, o sistema de juros multiplica seu lucro camuflado em oportunidade para os necessitados.

A nota de dólar, que fecha a última imagem (Fig. 2), traduz-se no próprio sistema capitalista, que orquestra um conjunto de mazelas, cuja "grana" dá origem a diversos problemas sociais. Em síntese, o problema do consumo atravessa toda a narrativa, não existe mal menor talvez diga a obra, todos fazem parte - a pobreza, a exploração ou o crime organizado - de problemas correlatos de um sistema social que elegeu o dinheiro como monarca - afinal, é ele quem manda.

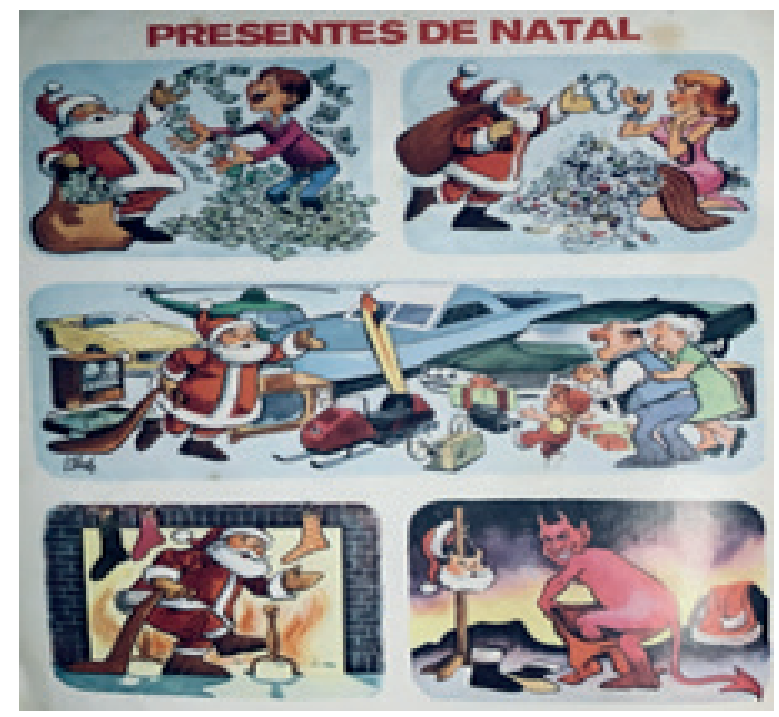

Fig. 3. CLARKE, Bob; JAFFEE, Al. Presentes de Natal. Fonte da figura: Revista MAD em Português, v. 7, 1974.

34 A paródia de programas televisivos foi uma marca da revista MAD, mas não apenas isso, o domínio que a televisão impõe à população também ganhou destaque em diversas sátiras durante o período áureo da publicação.

35 Ibidem, p. 116. 
Por fim, com mais uma contribuição de Al Jaffee, dessa vez em parceria do cartunista Bob Clarke (1926-2013), a representação do espírito natalino como uma grande festa do capital tornou-se o leitmotiv para mais uma vez satirizar a sociedade de consumo. A atmosfera de Natal feliz é construída pela expressão de alegria que atravessa todas as personagens e, como é possível perceber, pertencem à classe que tem maior poder de compra. Papai Noel distribui presentes e a crítica vai se construindo à medida que a fartura de mercadorias produzem a alegria do Natal. A faceta diabólica do bom velhinho, enquanto símbolo de uma cultura baseada na atividade econômica, engrena os mecanismos de consumo que edificam o sistema capitalista. A relação intertextual dialoga com as tradicionais propagandas natalinas que se resumem a propagandas de consumo. Logo, numa camada mais sutil, o tema da indústria cultural como ferramenta de controle aparece em cena. A produção capitalista mantém os homens presos sem resistência. Trata-se, citando Adorno e Horkheimer, "do esmagamento de toda resistência individual" ${ }^{36}$.

\section{Considerações finais}

Johan Huizinga (2004) quando escreveu o Homo Ludens, em 1938, advertiu sobre a manipulação de certas formas lúdicas a favor de desígnios políticos e sociais. Seis anos depois, Adorno e Horkheimer (1985) publicaram o ensaio A Indústria Cultural que trata dos mecanismos de dominação mediados pelo divertimento. A indústria cultural, ao mesmo tempo em que seria responsável pela criação de uma arte leve, também violaria a autonomia da arte, submetendo-a à lógica do capitalismo. No entanto, segundo Andreas Huyssen (1997), houve, nas últimas décadas, uma mescla entre aquilo que Adorno e Horkheimer chamavam de arte leve e arte séria.

Os meios de comunicação em massa, no contexto dos anos sessenta, romperam com a mera passividade e proporcionaram às massas uma arte desalinhada das políticas dominantes. O entretenimento, equilibrando-se entre a leveza e a seriedade, mostrouse capaz de refinar suas técnicas e assimilar uma postura emancipatória em seus modos de realização. A hibridização entre a cultura de massa e a crítica social adquiriu características que desafiam o conceito de indústria cultural, pois as qualidades críticas de uma arte leve são confirmadas nas mais diversas mídias de comunicação. O impacto que isso traz ao entretenimento e às artes, é inevitável, o que também possibilita com as novas tecnologias a criação de comunidades transnacionais.

36 Ibidem, p. 130. 
A revista MAD, aqui identificada como um produto híbrido, circulou por mais de vinte países. Seu time de artistas, com variados estilos e diversas nacionalidades, contribuiu para que a revista alcançasse o sucesso. Por mais que a multiplicidade de autores proporcione abrangentes pontos de vista, a postura crítica ante as incongruências da vida preserva o senso de unidade da revista. Temas de relevância social ganharam a voz e o perfil da publicação, que se caracterizava por oferecer um humor desafiador e rebelde.

Nosso intuito foi o de analisar a crítica ao consumismo a partir de exemplos pontuais, que revelam o alinhamento ideológico da revista desde sua concepção inicial. Os criadores da MAD, Harvey Kurtzman e William Gaines, contribuíram para que a publicação fosse mais do que uma revista inofensiva de humor, cada qual a seu modo, conjugaram a seriedade que se espera de uma arte capaz de realizar de maneira livre sua função questionadora na sociedade. A ausência de um alinhamento políticopartidário não corresponde à falta de engajamento com temas sociais. A luta por uma sociedade mais livre e igualitária começa pela tomada de consciência. Nesse sentido, as contribuições da MAD para a formação intelectual de diversos jovens ao redor do mundo é inegável.

Entendemos que o divertimento e a seriedade podem unir-se para a realização de uma autêntica obra de arte. Em seu auge, com milhões de cópias vendidas, a revista MAD demonstrou para um público jovem - a partir de uma arte leve e num veículo de comunicação em massa - uma prática contra-hegemônica, como reação aos valores que organizam e fundamentam uma sociedade capitalista. $\mathrm{O}$ engajamento crítico e o pensamento emancipatório são atributos de uma arte séria, que visa à formação de um homem integral. Do mesmo modo, o humor e a sátira são os ingredientes essenciais quando o riso se transforma na única resposta contra uma sociedade que consome, oprime e massifica. Sendo assim, a revista MAD soube como equilibrar o leve e o sério na formação de uma nova maneira de realizar o humor e a sátira.

\section{Referências Bibliográficas}

ADORNO, Theodor; HORKHEIMER, Max. Dialética do Esclarecimento: fragmentos filosóficos. Tradução de Guido Antônio de Almeida. Rio de Janeiro, Jorge Zahar, 1985.

BARROS, Otacílio Costa d'Assunção. Sou um contador de histórias. Revista BRAVO!, set. 2017. Disponível em: https:medium.com/revista-bravo/sou-umcontador-de-hist\%C3\%B3rias-8a7a217b18b. Acesso em: 12 fev. 2020. 
FONTENELLE, Isleide Arruda. Cultura do Consumo: fundamentos e formas contemporâneas. Rio de Janeiro, FGV, 2017.

GABLER, Neal. Life: The Movie: How Entertainment Conquered Reality. New York, Vintage Books, 2000.

HISS, Tony. The MAD. The New York Times, jul. 1977. Disponível em: https:// www.nytimes.com/1977/07/31/archives/the-mad-generation-after-25-years-ofperpetrating-humor-in-the.html. Acesso em: 11 jan. 2020.

HUIZINGA, Johan. Homo Ludens: o jogo como elemento da cultura. Tradução de João Paulo Monteiro. São Paulo: Perspectiva, 2004.

HUYSSEN, Andreas. Memórias do Modernismo. Tradução de Patrícia Farias. Rio de Janeiro: Editora UFRJ, 1997.

KOCK, Thomas Freeman. Que é um introvertido? Revista MAD em Português. Rio de Janeiro: Vecchi, n. 03, set. de 1974. p. 36-37.

MANDEL, Ernest. O Capitalismo Tardio. Tradução de Carlos Eduardo Silveira Matos. 2. ed. São Paulo: Nova Cultura, 1985.

MEYERSON STRATEGY: MAD Magazine founder William M. Gaines Interviewed in 1978. Entrevistador: Charlie Meyerson. Entrevistado: William Gaines. Chicago: ComiCon, 15 jul. 1978. Disponível em: https://www.meyersonstrategy. com/2011/07/mad-magazine-founder-william-m-gaines.html. Acesso em: 20 jan. 2020 .

REINT, Sy. A Cartilha MAD da Poluição. Revista MAD em Português. Rio de Janeiro: Vecchi, n. 17, nov. de 1975. p. 23.

RODRIGUES, Luciane Candido. A construção do conceito de Popular em Theodor Adorno. 2012. 85f. Dissertação (Mestrado em Filosofia) - Escola de Filosofia, Letras e Ciências Humanas, Universidade Federal de São Paulo, Guarulhos, 2012.

SALGADO, Daniel. O “fim” da MAD, maior revista de humor do mundo. Época. 07 jul. 2019. Disponível em: https:/ / epoca.globo.com/cultura/o-fim-da-mad-maiorrevista-de-humor-do-mundo-23789971. Acesso em: 12 fev. 2020. 
SANTOS, Roberto Elísio dos. Uma revista muito louca: análise do humor da MAD Magazine. São Paulo: Criativo, 2015.

SCHELLY, Bill. American Comic Book Chronicles: the 1950s. Raleigh: TwoMorrows, 2013.

SCHELLY, Bill. Harvey Kurtzman: the man who created MAD and revolutionized humor in america. Seattle: Fantagraphics, 2015.

THOMPSON, Ethan. Parody and Tasty in Postwar American Television Culture. Routledge: New York, 2011.

WELCH, Susan; GRUHL, John; COMER, John, RIGDON, Susan. Understanding American Government. 11. ed. Belmont: Thomson Wadsworth, 2008.

WILLIAMS, Raymond. Marxism and Literature. Oxford: Oxford University Press, 1978.

WILLIAMS, Raymond. Recursos da Esperança: Cultura, Democracia e Socialismo. Tradução de Nair Fonseca e João Alexandre Peschanski. São Paulo: UNESP, 2015. 